\title{
Ultrastructural analysis of testes from mice fed on genetically modified soybean
}

\section{Vecchio, ${ }^{1 *}$ B. Cisterna, ${ }^{1}$ M. Malatesta, ${ }^{2}$ T.E. Martin, ${ }^{3}$ M. Biggiogera ${ }^{1}$}

${ }^{1}$ Laboratorio di Biologia Cellulare e Neurobiologia, Dipartimento di Biologia Animale, University of Pavia and Istituto di Genetica Molecolare del CNR, Pavia, Italy; ${ }^{2}$ ststituto di Istologia ed Analisi di Laboratorio,

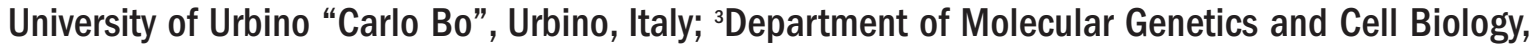
University of Chicago, IL, USA

*Present address: Centre of Electron Microscopy, Unversity of Lausanne, Switzerland

(C)2004, European Journal of Histochemistry

We have considered the possible effects of a diet containing genetically modified (GM) soybean on mouse testis. This organ, in fact, is a well known bioindicator and it has already been utilized, for instance, to monitor pollution by heavy metals.

In this preliminary study, we have focussed our attention on Sertoli cells, spermatogonia and spermatocytes by means of immunoelectron microscopy. Our results point out that the immunolabelling for Sm antigen, hnRNPs, SC35 and RNA Polymerase II is decreased in 2 and 5 month-old GM-fed mice, and is restored to normal at 8 months. In GM-fed mice of all ages considered, the number of perichromatin granules is higher and the nuclear pore density lower. Moreover, we found enlargements in the smooth endoplasmic reticulum in GM-fed mice Sertoli cells. A possible role played by traces of the herbicide to which the soybean is resistant is discussed.

Correspondence: Marco Biggiogera, Dipartimento di Biologia Animale, Laboratorio di Biologia Cellulare e Neurobiologia, University of Pavia, Piazza Botta 10, 27100 Pavia, Italy. Tel: +390382 986322 .

Fax: +390382986325

E-mail: marcobig@unipv.it

Paper accepted on November 3, 2004.

European Journal of Histochemistry

2004; vol. 48 issue 4 (Oct-Dec):449-454
G enetically modified (GM) crops are nowadays utilized for both human and animal consumption. Most of the modified crops have a foreign gene inserted into their genome in order to give resistance to pests or pesticides and this approach is effective in reducing the crop loss due to the above problems. Basically, the principle for considering these modified crops suitable for consumption is that of nutritional equivalence (Halford and Shewry, 2000).

There is, however, an apparent lack of studies in the scientific literature concerning possible effects of such GM crops on tissues and organs, both from the morphological and functional standpoint. Among the few data published on this topic it is worth considering the papers by Malatesta and coworkers (Malatesta et al., 2002a,b; 2003) on the effects of GM-diet in some organs related to digestion and/or food metabolism. These authors have shown some modifications (nuclear shape, number of nuclear pores, amylase detectability) in animals fed on GM diet. In this context we have studied on mice the effects of a diet containing GM soybean; this particular soybean is glyphosate-resistant (Padgette et al., 1995) and has been treated with the herbicide Roundup. This non selective herbicide is capable of inhibiting the plant to produce aromatic aminoacids by interfering with the shikimate pathway (Malik et al., 1989). We have considered the possible effects on the testis. This organ, in fact, is a well known bioindicator and it has been utilized, for instance, to monitor pollution by heavy metals (Guraya, 1987)

In this preliminary investigation, we have used immunoelectron microscopy to study Sertoli cells (which represent the only somatic cell type in the seminiferous tubule), spermatogonia and spermatocytes. 


\section{Materials and Methods}

Pregnant Swiss mice were fed on a standard laboratory chow containing 14\% GM soybean (Padgette et al., 1995). In parallel, other pregnant mice were fed on the same diet with wild type soybean. The respective litters were fed on the parental diet ( 12 controls and 12 GM-fed) and killed by cervical dislocation when 2, 5 or 8 months old.

For the morphological analysis, the testes were fixed in $2 \%$ glutaraldehyde, postfixed in $2 \% \mathrm{OsO}_{4}$ and embedded in Epon. For the immunocytochemical studies, the samples were fixed in $4 \%$ paraformaldehyde for $2 \mathrm{~h}$ at $4^{\circ} \mathrm{C}$ and embedded in LRWhite.

The following antibodies were used: a mouse monoclonal antibody recognizing the phosphorylated form of RNA Polymerase II (Research Diagnostics Inc.) diluted 1:50; a human autoimmune serum recognizing the Sm antigen of snRNPs (Lerner et al., 1981) diluted 1:200; a mouse monoclonal antibody against SC35 splicing factor (1:2) (Sigma) and a chicken anti-hnRNP core protein antibody diluted 1:500 (Martin e Okamura, 1981).

Ultrathin sections on formvar-carbon-coated nickel grids were incubated on normal goat serum (NGS) diluted $1: 100$ in PBS for 3 minutes, then the incubation with the primary antibodies, diluted in PBS- $0.05 \%$ Tween- $0.1 \%$ BSA, was performed at $4^{\circ} \mathrm{C}$ for $17 \mathrm{hrs}$. After rinsing with PBS-Tween and PBS, the grids were incubated with NGS as above. For the monoclonal antibodies, we used a secondary goat anti-mouse IgG+IgM (Jackson Immuno Research Laboratories Inc.); for the autoimmune antibody, a goat-anti-human IgG (Jackson Lab.) and, for the antibody raised in the chicken, a donkey anti chicken IgY (Jackson Lab); all the secondary antibodies were coupled with $12 \mathrm{~nm}$ colloidal gold and diluted $1: 20$ in PBS and the incubations were carried out for $30 \mathrm{~min}$ at room temperature. As a control, some grids were floated on the incubation mixture without the primary antibody and incubated with the appropriate secondary antibody.

Immunolabelled ultrathin sections were stained either with the EDTA method (Bernhard, 1969) to visualize RNP constituents, or with terbium citrate (Biggiogera and Fakan, 1998; Trentani et al., 2003) for selective RNA staining; Epon sections were conventionally stained with uranyl-lead. All samples were observed in a Zeiss EM 900 electron microscope operating at $80 \mathrm{kV}$. The gold grain contrast was digitally enchanced on the scanned micro- graphs using Adobe Photoshop.

Morphometrical analyses were performed on 40 electron micrographs (10 for each condition: 2 months old control, 2 months GM, 8 months controls, and 8 months GM) of Sertoli cell nuclei, taken at a magnification of 7,000x on LRWhite sections. Perichromatin granule density $\left(P G / \mu m^{2}\right.$ of total nuclear area) and nuclear pore density (nuclear pore number/um of nuclear perimeter) were considered. For the quantitative evaluation of anti-hnRNP immunolabelling, 40 electron micrographs (10 for each condition) of spermatocytes were taken at a magnification of 20,000x. The labelling density was always expressed as the number of colloidal gold grains/ $\mu^{2}$ of nucleoplasmic area. For each variable the ANOVA test was performed; significance level was fixed at $p \leq 0.01$.

\section{Results}

The Sertoli cells from GM-fed mice of all ages showed enlarged vescicles of the smooth endoplasmic reticulum (SER) (Figure $1 A$ ) which were not present in the control testis (not shown). The nucleoli appeared larger and more reticulated in 2 and 5 month-old mice fed on GM-diet (Figure. 1C) than in controls (Figure 1B); on the contrary, no difference was observed in nucleolar morphology in the majority of cells at 8 month of age (not shown).

In both Sertoli and germ cells of all animals considered the appearance and general distribution of the nucleoplasmic components involved in transcription and splicing were similar in control and GM-fed mice. However, at all the ages considered, a statistically significant increase in perichromatin granules ( $P G$ ) was observed not only in Sertoli cells but also in spermatocytes of GM-fed mice (Figure $1 \mathrm{E}$ and Table 1 ). Interestingly enough, a decrease in the number of nuclear pores (NP) was also detected in GM-fed mice.

An immunolabelling was also performed for the splicing factor Sm, which is located on perichromatin fibrils (PF) and interchromatin granules (IG):both in Sertoli and germ cells the labelling was reduced in 2 and 5 month-old GM-fed mice compared to their controls (Figures 1D-E). SC35 as well as RNA polymerase II labelling was also lower in 2 and 5 month-old GM-fed mice, whereas, in GM-fed 8 month-old mice, it was restored to the control level (not shown).

In GM-fed mice we have also observed a reduced 

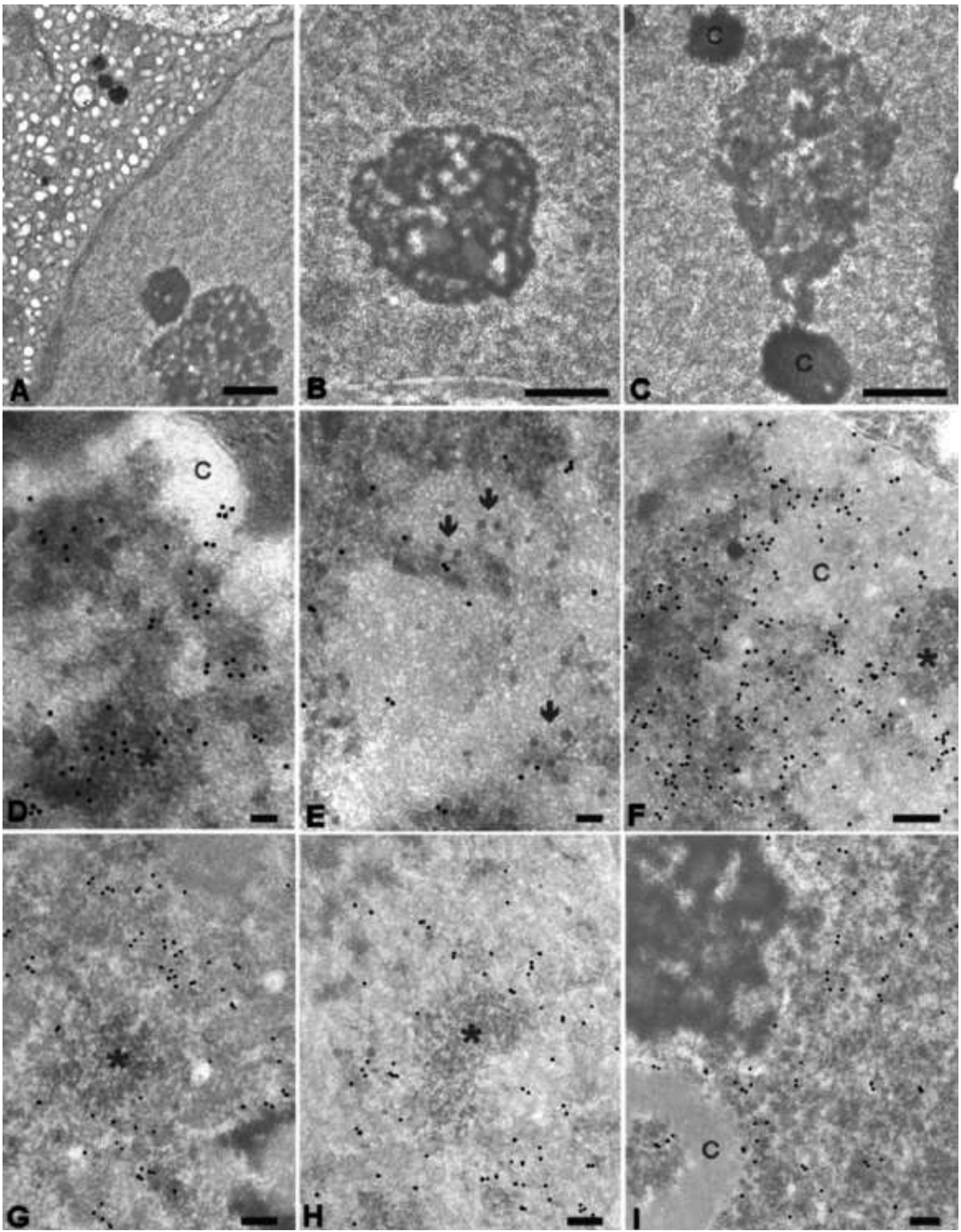

Figure 1. A-C: Glutaraldehyde-0smium fixation. A: 2 month-old GM-fed mouse. In the cytoplasm of Sertoli cell the enlargement of SER is evident. bar=1 $\mu \mathrm{m}$. B: $\mathbf{2}$ month-old control mouse. A typical nucleolus of a Sertoli cell constituted by large fibrillar centres and an abundant dense fibrillar component. bar=1 $\mu \mathrm{m}$. C: 2 month-old GM-fed mouse. Most of the nucleolus is constituted by the granular component. Fibrillar centres are rare. C=typical chromatin associated to nucleoli in Sertoli cells. bar=1 $\mu$ m. D-I: Paraformaldehyde, fixation EDTA staining. D: 2 month-old control mouse, primary spermatocyte. The labelling for Sm is localized at the periphery of chromatin (C) on PF as well as on IG (asterisk). bar=0.1 $\mathrm{mm}$. E: 2 month-old GM-fed mouse, primary spermatocyte. The labelling for Sm is less rapresented than in control. Note the abundance of PG (arrows). bar=0.1 $\mu \mathrm{m}$. F: 2 month-old control mouse, primary spermatocyte. The labelling for hnRNP core protein is abundant on PF and absent from IG (asterisk). C= chromatin. bar=0.2 $\mu \mathrm{m}$. G: 2 monthold GM-fed mouse, primary spermatocyte. The labelling for hnRNP is less abundant when compared with the respective control. Asterisk= IG. bar $=0.2 \mu \mathrm{m}$. H: 8 month-old control mouse, primary spermatocyte. The labelling for hnRNP is correctly localized on PF and absent on IG (asterisk). bar=0.2 $\mu \mathrm{m}$. I: 8 month-old GM-fed mouse, Sertoli cell. The labelling for hnRNP is similar to that shown in $1 \mathrm{H}$. $\mathrm{C}=$ chromatin. bar $=0.2 \mu \mathrm{m}$. 
Table 1. Means \pm SD values of variables considered in Sertoli cells. The values are all significantly different.

\begin{tabular}{lll}
\hline \hline Age & $P G$ density & NP density \\
2 months (C) & $0.62 \pm 0.49$ & $0.93 \pm 0.22$ \\
2 months & $1.18 \pm 0.68$ & $0.77 \pm 0.15$ \\
8 months (C) & $0.56 \pm 0.31$ & $1.75 \pm 0.48$ \\
8 months & $0.82 \pm 0.37$ & $0.97 \pm 0.38$ \\
\hline
\end{tabular}

C: control animals.

Table 2. Means \pm SD values of anti-hnRNP labelling (gold grains $/ \mu \mathrm{m}^{2}$ ) on spermatocytes. The values identified by an asterisk are not significantly different.

$\begin{array}{ll}\text { Age } & \text { Anti-hnRNP labelling } \\ 2 \text { months (C) } & 50.94 \pm 6.90 \\ 2 \text { months } & 11.63 \pm 5.63 \\ 8 \text { months (C) } & 22.69 \pm 7.55^{*} \\ 8 \text { months } & 24.89 \pm 6.81^{*}\end{array}$

C: control animals.

immunolabelling for hnRNP in 2 and 5 month-old mice, in all cells considered, the gold grains being still specifically present on PF and absent from IG (Figures IF-G). On the contrary, at 8 months, we have found that the hnRNP labelling in GM-fed mice (Figure 1I) was similar to the corresponding controls (Figure $1 \mathrm{H}$ ). It must be noted that the labelling for hnRNP at this age was lower than at 2 or 5 months. The results of the quantitative evaluation of the anti-hnRNP labellings are shown in Table 2.

\section{Discussion}

Our results point out that, in GM-fed mice:

- the immunolabelling for Sm, hnRNPs, SC35, and RNA polymerase II decreased in 2 and 5 monthold animals and was restored to the control levels at 8 months, in both Sertoli and germ cells;

- the number of PG was higher and the NP density lower than in controls;

- dilated vescicles of the SER occured in Sertoli cells.

These findings suggest that, during the 2-8 months interval, a transient transcriptional decrease occurs in mice fed on the GM-diet. In fact, during this time period clusters of PG (which are known to contain pre-mRNA: Fakan, 2004) were found in all cell types examined; if we consider that the NP density was also significantly lower, the accumulation of $P G$ is likely to result from an inadequate processing/export of (pre)mRNAs from the nucleus. These results are in agreement with the findings of Malatesta et al. (2003) on pancreatic cell nuclei of mice fed on GM soybean.

Stress factors or drugs inhibiting translation are known to determine $P G$ accumulation in the nucleus as the result of a feedback mechanism acting on nuclear function (Fakan and Puvion, 1980). We may hypothesize that a similar mechanism might be active in the testicular cells of GM-soybean-fed mice where the reduction of transcription takes place in parallel with a decrease in NP density, thus determining the nuclear accumulation of RNAs in the form of $P G$.

Drug-induced reduction in hnRNA synthesis has been reported to result in an increased nucleolar activity (Petrov and Sekeris, 1971); this is consistent with our morphological observation: nucleoli, in fact, are more reticulated in GM-fed mice. This fact is normally related to a higher activity (Schwarzacher and Wachtler, 1993).

Some of the observed changes in the characteristics of testicular cells proved to be reversible in 8month-old mice fed on the GM diet, probably due to compensation mechanisms. SER dilation is, on the contrary, irreversible at 8 months. Further studies are in progress to elucidate this these latter modification can affect mouse fertility.

The cause(s) of the observed alterations cannot be conclusively established, at this stage of the research. However, since the GM soybean used in the present investigation was glyphosate-resistant and was consequently treated in the field with such a herbicide, the possibility cannot be ruled out that the effects observed may be due to the herbicide residues. Consistent with this hypothesis, traces of glyphosate have actually been detected in milling and bread from treated GM-soybean (Granby et al. 2003). Although a direct evidence does not exist for an effect of glyphosate on transcription and translation, it has been shown that it generates DNA adducts (when used at high doses: Peluso et al., 1998) and cell division dysfunction (when administered at low doses, Marc et al., 2002). The presence of residual glyphosate could also account for the presence of SER enlargements in Sertoli cells: in fact, Walsh et al. (2000) reported that glyphosate affects SER-related steroidogenesis through the disruption of StAR protein expression. 


\section{Acknowledgements}

The skillful technical help of Ms.Francine Flach is acknowledged. This work was supported by the Italian Ministry of University and Research (PRIN 2002) and by the Fondo di Ateneo per la Ricerca (FAR 2002, Pavia University). The mice were bred at the Istituto Zooprofilattico Sperimentale dell'Umbria e delle Marche: the technical assistance of Mr. Sorcionovo is gratefully acknowledged.

\section{References}

Bernhard WA. New staining procedure for electron microscopical cytology. J Ultrastruc Res 1969; 27:250-65.

Biggiogera M, Fakan S. Fine structural specific visualization of RNA on ultrathin sections. J Histochem. Cytochem 1998; 46:389-95.

Fakan S, Puvion E. The ultrastructural visualization of nuclear and extranucleolar RNA synthesis and distribution. Int Rev Cytol 1980; 65:255-99.

Fakan S. Ultrastructural cytochemical analyses of nuclear functional architecture. Eur J Histochem 2004; 48: 5-14.

Granby K, Johannesen S, Vahl M. Analysis of glyphosate residues in cereals using liquid chromatography-mass spectrometry ( LCMS/MS). Food Addit Contam 2003; 20:692-98.

Guraya SS. Biology of spermatogenesis and spermatozoa in mammals. Springer Verlag, Berlin, heidelberg, NewYork, London, Paris, Tokyo 1987.

Halford NG, Shewry PR. Genetically modified crops: methodology benefits regulation and public concerns. Br Med Bull 2000; 56:62-73.

Lerner EA, Lerner MR, Janeway CA, Steitz J. Monoclonal antibodies to nucleic acid-containing cellular constituents: probes for molecular biology and autoimmune diseases. Proc Natl Acad Sci USA $1981 ; 78: 2737-41$
Malatesta M, Caporaloni C, Gavaudan S, Rocchi MBL, Tiberi C, Gazzanelli G. Ultrastructural morphometrical and immunocytochemical analyses of hepatocyte nuclei from mice fed on genetically modified soybean. Cell Struct Funct 2002a; 27:173-80.

Malatesta M, Caporaloni C, Rossi L, Battistelli S, Rocchi MBL, Tonucci $F$, et al. Ultrastructural analysis of pancreatic acinar cells from mice fed on genetically modified soybean. J Anat 2002b; 201:409-16.

Malatesta M, Biggiogera M, Manuali E, Rocchi MBL, Baldelli B, Gazzanelli $G$. Fine structural analyses of pancreatic acinar cell nuclei from mice fed on GM soybean. Eur J Histochem 2003; 47:385-88.

Malik J, Barry G Kishore G. The herbicide glyphosate. Bio Factors $1989 ; 2: 17-25$.

Marc J, Mulner-Lorillon 0, Boulben S, Hureau D, Durand G, Belle R. Pesticide Roundup provokes cell division dysfunction at the level of CDK1/cyclin B activation. Chem Res Toxicol 2002; 15:326-31.

Martin TE, Okamura CS. Immunocytochemistry of nuclear hnRNP complexes. In: Bush H (ed) The cell nucleus 1981; 9:119-44.

Padgette SR, Kolacz KH, Delannay X, Re DB, LaVallee BJ, Tinius CN, et al. Development identification and characterization of $a$ glyphosate-tolerant soybean line. Crop Sci 1995; 35:1451-61.

Peluso M, Munnia A, Bolognesi C, Parodi S. 32P-postlabeling detection of DNA adducts in mice treated with the herbicide Roundup. Environ Mol Mut 1998; 31:55-9.

Petrov $\mathrm{P}$, Sekeris CE. Early action of alpha-amanitin on extranucleolar ribonucleoproteins, as revealed by electron microscopic observation. Exp Cell Res 1971; 69:393-401.

Schwarzacher HG, Wachtler F. The nucleolus. Anat Embryol 1993; 188:515-36.

Trentani A, Testillano PS, Risueno MC, Biggiogera M. Visualization of transcription sites at the electron microscope. Eur J Histochem 2003;47:195-200.

Walsh LP, McCormick C, Martin C, Stocco DM. Roundup inhibits steroidogenesis by disrupting steroidogenic acute regulatory (StAR) protein expression. Environ Health Perspect 2000; 108:769-76. 
L. Vecchio et al. 